\title{
Evaluation of Safety and Security by Using the Fuzzy Logic Methods in Islamic Azad University, Branch of Lahijan
}

\author{
Hedyeh Rastkar Komachali; ; Sudabeh Nowruzi \\ Email: Hedirastkar@gmail.com
}

http://dx.doi.org/10.18415/ijmmu.v4i2.72

\begin{abstract}
Safety assumes a critical part in the utilization of spots. Various spots can create issues in respect to people's impression of safety. A few parameters influence the view of security and various scientists have dug into these parameters. In any case, large portions of these parameters are quantitative and hard to break down utilizing ordinary expository strategies. This paper at first recognizes the parameters that influence safety by utilizing a survey. These parameters incorporate the components of light, crowdedness, and scene. A short time later, these parameters are measured in three places inside the Islamic Azad University, Lahijan branch. An assessment of the security of these spots in view of the fluffy rationale framework takes after. Finally, we watched that after effects of the fluffy rationale examination demonstrated generous concurrence with the survey discoveries.
\end{abstract}

Keywords: Security; safety; fuzzy logic

\section{Introduction}

The relationship between landscape and human has been extensively studied in various fields, such as urban design, human geography, landscape architecture, and environmental psychology. Understanding this relationship crucial in building a better and more comfortable residential environment than before. Safety is an important parameter in considering the use of a place including open spaces such as parks (Sreetheran \& van den Bosch, 2014). People search their environment for signs of danger, which they attempt to escape (Goffman, 2009). In places like university campus the presence of numerous bushes, bad lighting, hiding places, limited gates and dark hallways foe escape are related to level of safety (Steinmetz \& Austin, 2013).Although these factors are related to level of safety, the effect of these parameters differ according to gender, age and education. Considerable research on safety has been conducted on the university campus to limit the parameters that impact safety (Baum \& Klaus, 2005; Bledsoe \& Sar, 2001; McConnell, 1997).

Landscapers and urban designers have designed safer and better places, by employing Crime Prevention Through Environmental Design (CPTED) methods. Crowe (2000)defined CPTED as "the proper design and effective use of the built environment can lead to a reduction in the fear of crime and the incidence of crime, and to an improvement in the quality of life". This method (CPTED) includes the landscape management and design necessary to reduce the chance of the occurrences of crimes, which is 
based on the hypothesis that an offender enters a logical decision-making process prior to committing a criminal act. Generally, designers need the numerical values to produce objective outcomes from their statistical and other empirical analyses. On the other hand, parameters such as the light, safety, and vegetation are expressed qualitatively (Fisher \& Nasar, 1992). Therefore, these parameters are not crisp. They are vague and impossible to define accurate and clearly instead. However, these parameters are useful in analyzing, assessing, and designing places for crime prevention. These non-crisp parameters are consistent with the imprecise nature of crime occurrence and impact. Traditional quantitative analyses methods are unsuitable for analyzing these imprecise parameters, particularly, when they are used to examine or assess the level of safety or fear of the crime in the place. Several researchers solely utilize observation methods to evaluate CPTED (Hedayati, 2009; Minnery \& Lim, 2005) which is observed to include certain drawbacks because it does not consider the residents " perceptions, responsibilities and actions towards CPTED elements (Sakip, Johari, \& Salleh, 2012).

Fuzzy logic is a useful method that assists to analyze the above mentioned parameters. Fuzzy logic permits the use of mathematical operations to operate and manipulate imprecise information or knowledge associated with CPTED, with the aim of designing safe and secure places. In this research, the safety of a number of places in the main campus of the Islamic Azad University, Lahijan branch is evaluated by using fuzzy logic methods, which are later compared with questionnaire results.

\section{Methodology}

\subsection{Questionnaires}

Two different questionnaires have been designed for this research project. The first questionnaire measured elements that affect the safety assessment and level in three places. The second questionnaire defined the membership function of parameters that affection safety. Respondents of both questionnaires consisted of a convenient random sample of students at the Islamic Azad University, Lahijan branch, which is a public university with an enrollment of over 2,000 students. Participants represented a various majors from 10 schools. This study was conducted in the Islamic Azad University, Lahijan branch.

A total of 487 was the sample size for the first questionnaires of this study, with a $90 \%$ response rate for this survey. The survey involved 540 respondents, only 313 of which were usable owing to incomplete fields and errors. The mean age of respondents was 24.15 years. Furthermore, 264 of the respondents were female and 221 were male. Only $21(6.1 \%)$ of the students experienced victimization in or out of campus. Sample characteristics are shown in Table 1. The first part of this questionnaire asked students about the effect of six different parameters on safety (Light, Landscape Elements, Street Pattern, Security System, Access Control (physical barriers), and Escape). The last part asked respondents about the safety levels of three different places in the university. Sample size for the second questionnaire was 100, 69 of whom were female and 31 were male. 
Table 1 Student Patient demographic variables $(\mathrm{N}=489)$

\begin{tabular}{|c|c|c|c|}
\hline Variables & Frequency (Percentage) & Male & Female \\
\hline \multicolumn{4}{|l|}{ Sex } \\
\hline Male & 225 & $147(65.3 \%)$ & - \\
\hline Female & 264 & - & $264(53.99 \%)$ \\
\hline Total & 489 & - & 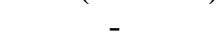 \\
\hline \multicolumn{4}{|l|}{ Education } \\
\hline Under grad & $326(66.7 \%)$ & $147(65.4 \%)$ & $179(67.9 \%)$ \\
\hline Post grad & $163(33.3 \%)$ & $78(34.6 \%)$ & $85(32.1 \%)$ \\
\hline \multicolumn{4}{|l|}{ Resident status } \\
\hline In campus & $373(76.3 \%)$ & $147(65.3 \%)$ & $226(86.6 \%)$ \\
\hline Out campus & $116(23.7 \%)$ & $78(34.6 \%)$ & $38(14.4 \%)$ \\
\hline \multicolumn{4}{|l|}{ Victimization } \\
\hline Own experience & $26(5.3 \%)$ & $17(7.5 \%)$ & $9(3.4 \%)$ \\
\hline Friends experience & $73(15 \%)$ & $31(13.78 \%)$ & $42(16 \%)$ \\
\hline Age (average) & 24.15 & 22 & 26 \\
\hline \multicolumn{4}{|c|}{ Walk alone on campus at night } \\
\hline No & $114(23.3 \%)$ & $12(5 \%)$ & $102(38.6 \%)$ \\
\hline yes & $375(76.6 \%)$ & $213(95 \%)$ & $162(61.3 \%)$ \\
\hline
\end{tabular}

\subsection{Fuzzy Logic}

The concept of fuzzy logic was first used by Blockley $(1975,1979)$, Brown $(1979,1980)$ and Yao (1980) on safety although these studies focused on the safety of building structures. Afterwards, the fuzzy logic concept was used to evaluate the performance and safety of temporary structures (Hadipriono, 1985, 1988) as well as the safety of construction workers (Hadipriono \& Fujino, 1994). To examine numerous subjective evaluations against crime the concept of fuzzy logic was used for the first time by Tseng et al. (2004). In this case, Tseng et al. (2004) evaluated the safety of the campus garage. The application of fuzzy logic methods to assess the safety of campus locations was further explained in his study. Furthermore, the use of these methods can be extended toward other places.

In such a research project, to express various levels of truth and certainty as well as adjectives and adverbs are commonly used. These adjectives and adverbs are imprecise and incorporate a personal meaning for each person using them. For example, parameters such as "an unsafe place" and "low light" are imprecise. A fuzzy set is determined by pairs of fuzzy elements (inputs and outputs) which are defined by their membership functions.

Figure 1 shows the fuzzy set used for evaluating safety in this research. The membership functions represent the membership degree of the fuzzy set in the discourse universe. Membership can take any value between 0 and 1. The membership of each effective element is shown in Figure 2. This membership function was extracted directly from Questionnaire 2. In this questionnaire, 10 places were shown to the respondent, who was asked to mark the place's level of light vegetation and crowdedness. Lux Metreswas used to measure light. As light intensity is highly related to the distance from the source to the place being measured, the darkest point was measured for each place (the farthest place from the light source). To 
measure crowdedness, the number of the people who moved to and from the place between $7.30 \mathrm{PM}$ to 11.30 PM over the course of a week was counted and this number was divided by the total counting hours (28) to determine the average for each person who passes through this place (this counting process was performed from October 8 to 15). The road was divided in two lengths to measure the integration of the vegetation including the length of bushes and trees around (Equation 1). The schematic of this calculation is shown in Figure 3.

$$
v_{r}=\frac{\sum_{i=0}^{n} d_{i}}{2 l}
$$

\section{Equation 1}

Where $l$ is the road length, $d$ the diameter of tree or length of the bush, and $n$ is the number of trees and bushes. Fuzzy sets are frequently expressed in propositions as the condition and premise of an implication rule by if-then statements. Examples of these rules are",, if light is adequate, and crowdedness is high, and vegetation is low, then user may consider place is very safe. "A total of 27 rules were defined for this fuzzy logic system.

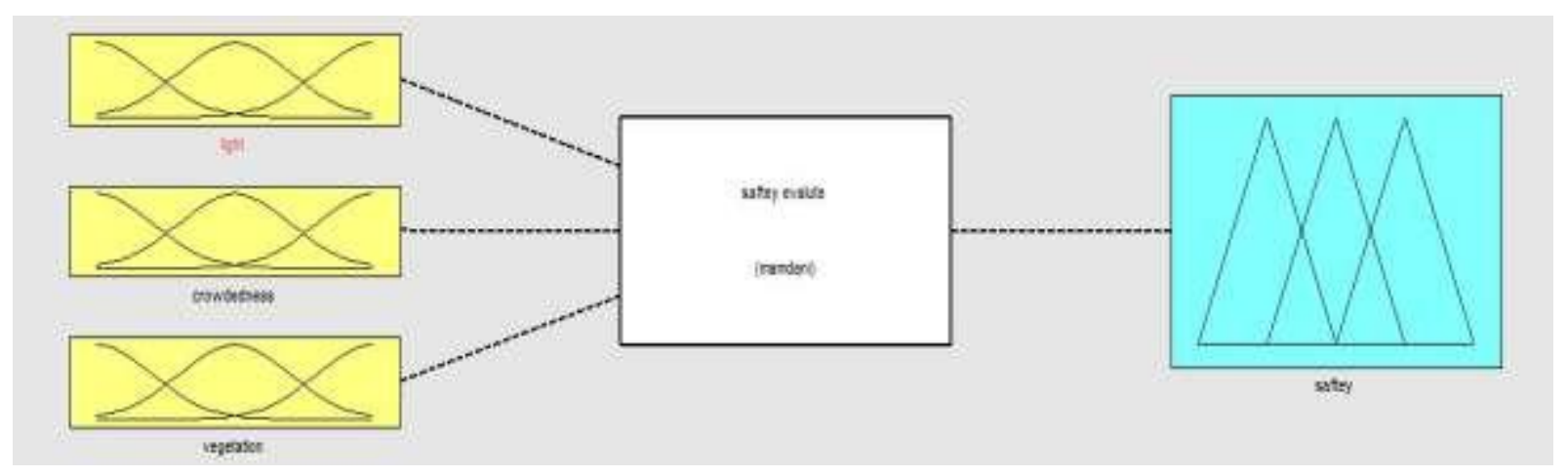

Fig. 1 Fuzzy logic inputs and output 


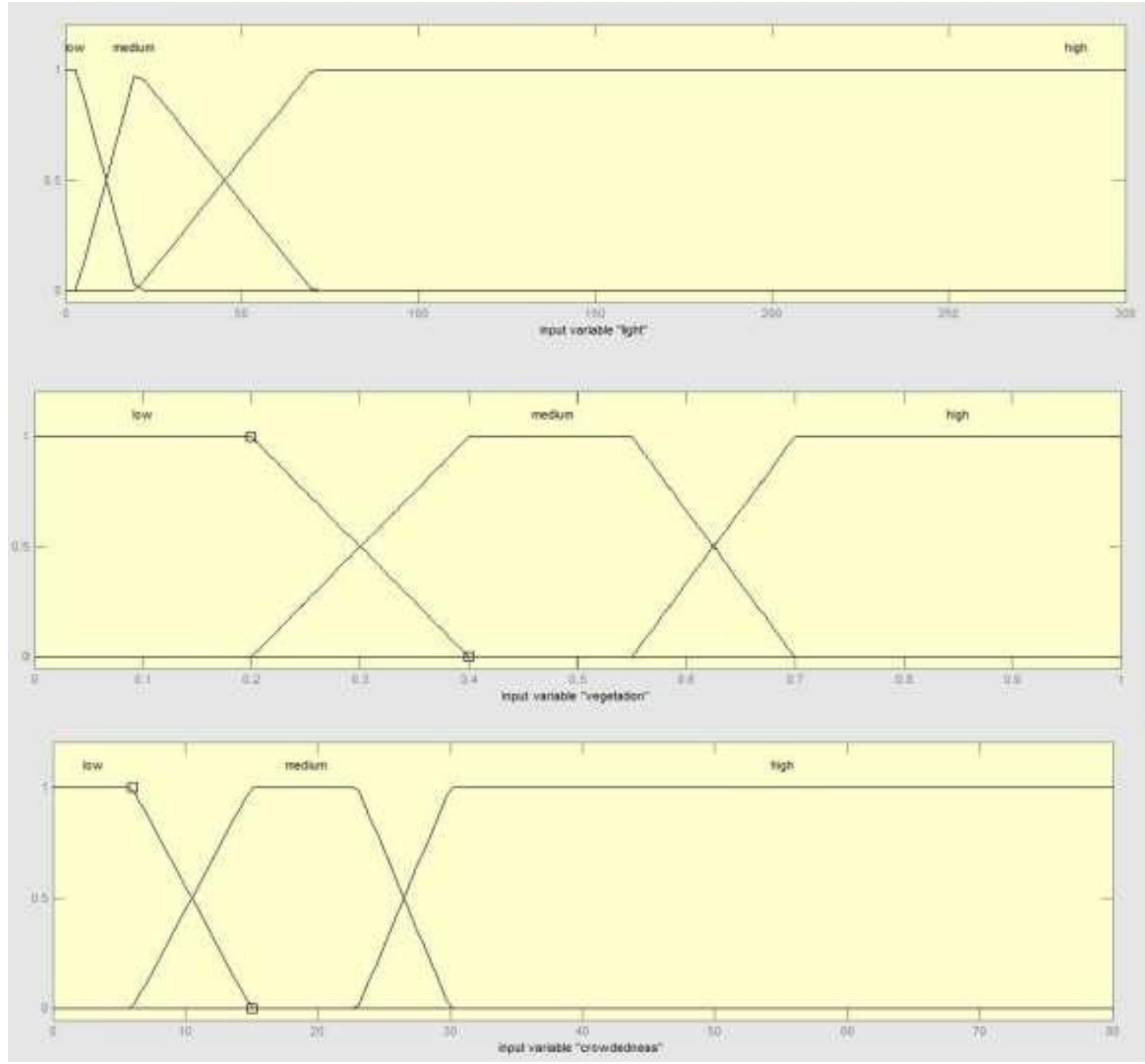

Fig. 2 Membership function of inputs

\section{Result and Discussin}

Safety depends on different parameters. Fisher and Nasser (1992) mentioned the prospects of refuge and escape as well as light as the three important parameters that impact the pedestrians ${ }^{\text {ee }}$ feelings of safety. However, these parameters are not the only essential parameters. In the first questionnaire the impact of seven parameters (Light, Landscape element, Street pattern, Security system, Access control (Physical barrier), Crowdedness and Escape) on the feelings of safety among respondents was examined. The effect of each parameter on feelings of safety is showed in Table 2. 


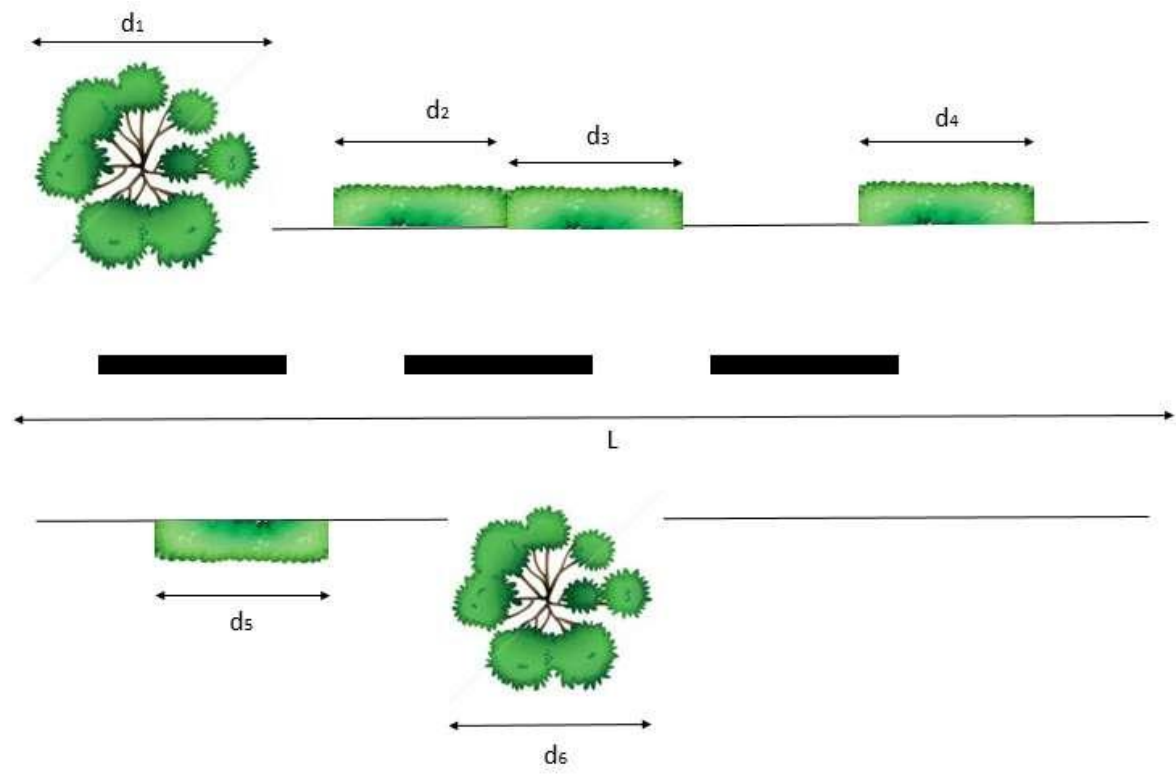

Fig. 3 Schematic of vegetation

Table 2 The evaluation of the important parameter that effect on safety $(N=489)$ Frequency (Percentage)

\begin{tabular}{lccc}
\hline Variables & Non-effect & Neutral & Effect \\
\hline Light & $34(0.6 \%)$ & $44(9 \%)$ & $442(90.4 \%)$ \\
Landscape element & $22(4.5 \%)$ & $54(11 \%)$ & $413(84.6 \%)$ \\
Street pattern & $283(57.9 \%)$ & $102(20.8 \%)$ & $104(21.3 \%)$ \\
Security system (CCTV) & $191(39.1 \%)$ & $96(19.6 \%)$ & $202(41.3 \%)$ \\
Escape & $328(67.1 \%)$ & $48(9.8 \%)$ & $113(23.1 \%)$ \\
Crowdedness & $5(1 \%)$ & $36(7.4 \%)$ & $448(91.6 \%)$ \\
Access control (Physical barrier) & $35(7.2 \%)$ & $29(5.9 \%)$ & $425(86.9 \%)$ \\
\hline
\end{tabular}

According to Table 2, most respondents agree that the four parameters of light, landscape element, crowdedness, and access control are affect feelings of safety. Moreover, the parameter escape which Fisher (1992) considered minimally affected respondents in feeling safe. Questionnaire results further show that safety is not easily defined. Moreover, questionnaire results indicate that numerous responders were confused between safety and security with during the assessment. Security is defined as the physical protection of property against lost or the risk of damage to these properties, whereas safety is defined as human well-being pertaining to the surrounding environment. 
Three of these parameters were selected as input parameters to analyze campus locations using the fuzzy logic system (Fig. 1). The parameter of access control was neglected because all the places in campus presented the same access control. However, using the input parameter was better to evaluate other places. By denying access to targets and raising the sense of safety among offenders, access control can increase safety and security by reducing the chance of crimes taking place (Larimian, Zarabadi, \& Sadeghi, 2013).

Based on the questionnaire results, light was the most important parameter that affected feelings of safety among the respondents, after the Crowdedness element, which has a small difference of only $1.2 \%$. In addition, respondents made numerous references to poor and inadequate lighting as an important issue in reducing safety levels. Dark areas were also mentioned to correspond to increasing fear of crimes, particularly among females (Sreetheran \& van den Bosch, 2014).

Landscape was the third most important parameter with $84.6 \%$ of responders agreeing that this parameter affected safety levels. Poor landscape design was seen to reduce safety, as it included the lack of spatial design and improper species selection. Landscape design was thought to improve safety. Dense and poorly managed vegetation was another major cause of fear of crime. People believed that dense bushes and shrubs were potential places for offenders to hide in. Large shrubs and dense trees primarily reduce visibility, which can present opportunities for conducting criminal activities. Landscape designers can improve the safety of the place by removing dense shrubs and by including these parts in their design elements. People preferred locations with wide and open views because they felt safer in such places, whereas the fear of crime increased when the view was blocked by vegetation. Landscape designers should therefore respond in their designs to address this desire for safety on the part of the people (Brower, Dockett, \& Taylor, 1983; Kuo, Bacaicoa, \& Sullivan, 1998; Kuo \& Sullivan, 2001).

In this paper, three different places were selected in the campus for the evaluation of their safety levels; the lists of these three places are presented in Table 3. The levels of light, crowdedness and vegetation of these three places have been measured. A picture of these three places is shown in Figure 4.

Table 3 Input parameters for the 3 places that examined

\begin{tabular}{lccc}
\hline Name of place & Light (LUX) & $\begin{array}{c}\text { Crowdedness } \\
\text { (Person/hour) }\end{array}$ & Vegetation \\
\hline 1) Main hall & 140 & 35 & 0.35 \\
2) Mosque & 30 & 0.5 & 0.65 \\
3) Main entrance & 1 & 4 & 0.5 \\
\hline
\end{tabular}

One of the places selected for this study is in the center of the university (Figure 4 (a)), which is located between two squares. In this location, two banks ensure that this place has adequate light to enable numerous people and cars to cross it at night. The Mosque is located in the north-west of the campus close to the Islamic Azad University, Lahijan branch Mosque. Big trees that remained in the rainforest was surrounded by the Mosque. Figure 4 (b) shows the location of the Mosque. This place was sufficiently light, although it is very far from the center of the university and the dormitory. Thus, people rarely cross this place at night. This part of the university does not benefit from landscape design as well. The third place is a Main entrance path that students use for fast access to the main gate of the university. This location is shown in Figure 4 (c). This place is not a road that students use frequently (the black line in Figure 4 (c) shows the path where the students cross) because it does not have enough light and a number of trees in the area increase darkness. 
These three places were examined using the fuzzy logic system with the results of this analysis then compared with the questionnaire result. The fuzzy logic analysis and the questionnaire results were significantly consistent. The fuzzy logic system shows that the Main hall has the highest level of safety across all these places, whereas the Main entrance has the lowest safety level. Results of the fuzzy logic method are compared to the questionnaire results in Table 3.

Fuzzy logic systems show good agreement for the safety of the Main hall and Mosque, whereas the error fuzzy logic methods and real safety in the Main entrance is maximum (around 5\%). The difference between fuzzy logic methods and real safety is acceptable and very near to each other. This shows that fuzzy logic methods can do acceptable estimates for the safety level of the place. Through this method, a designer can improve their design before construction. Crowdedness contributes in fostering high levels of safety as well.

Table 4 Comparison between the result of fuzzy logic method and questioner

\begin{tabular}{lccc}
\hline Name of place & Safety in fuzzy logic & Safety questioner & Error \\
\hline Main hall & $86 \%$ & $88 \%$ & $2 \%$ \\
Mosque & $30.8 \%$ & $33 \%$ & $3 \%$ \\
Main entrance & $13 \%$ & $18 \%$ & $5 \%$ \\
\hline
\end{tabular}

One of the reasons for the low safety level of the Mosque and the Main entrance is their underdesigned, wild landscape which diminished safety even when adequate light was provided. An improved landscape design (even a simple one) can enhance safety.

However, extending this study to other places, especially a place with specific applications such as a hospital or nursery, the definition of the safety should be examined given that the definition of safety is differed from one person to another one. Hence, it is not just a question of simply defining safety, because it is equally important to understand it. In fact, defining safety is closely related to people's experience (Tseng et al., 2004). Moreover, other personal parameters, such as age, race, sex, residency and education play important roles in safety (Steinmetz \& Austin, 2013). However, all of these parameters are neglected in the fuzzy logic method. Therefore, if we are to extend this research to other places, the personal parameters of the people who desire to use these places must be added to the fuzzy logic system as input parameters. 

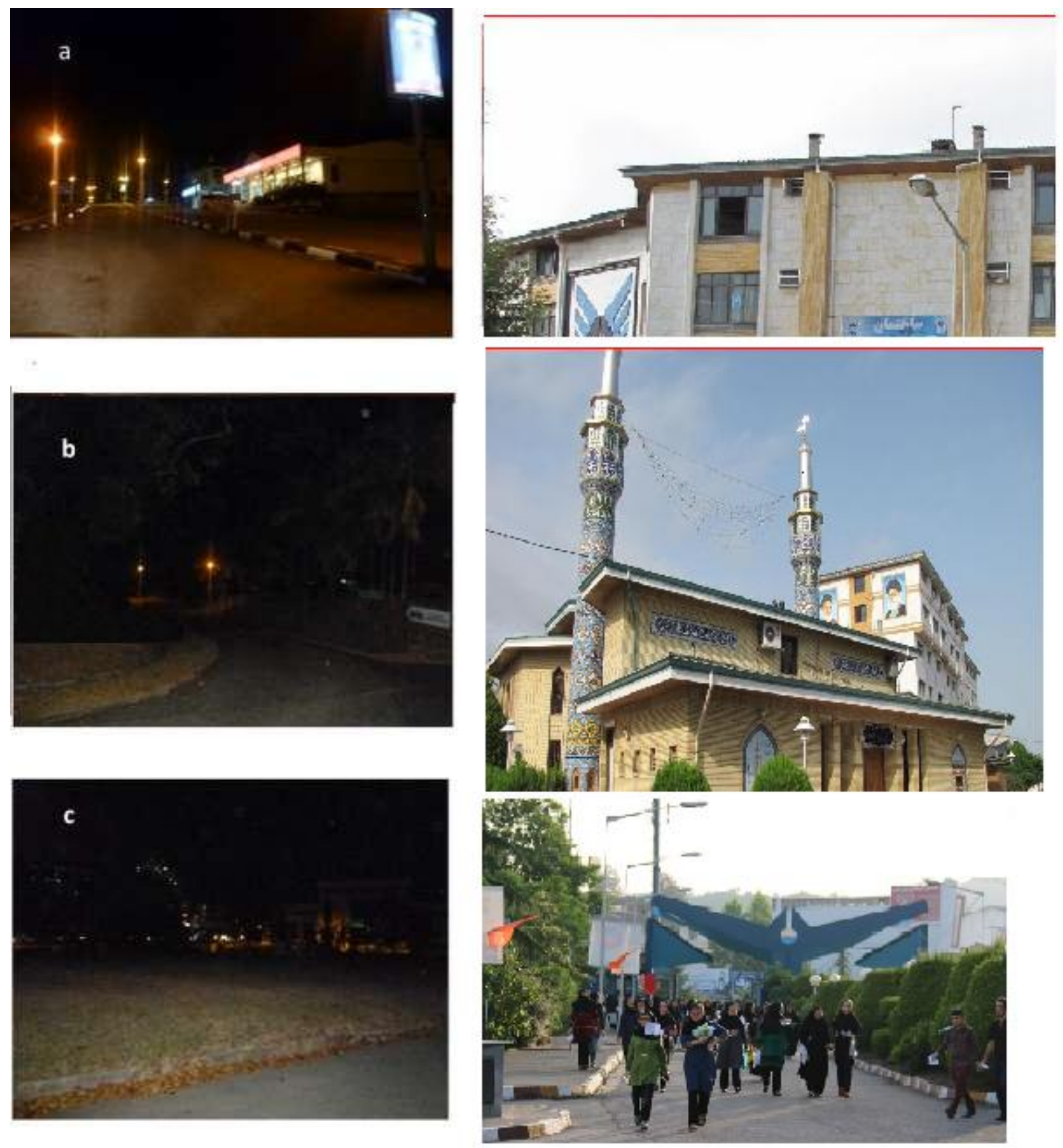

Fig. 4 a) Main hall, b) Mosque, and c) Main entrance

\section{Conclusion}

For this study, three campus locations were selected and safety of these places was examined using fuzzy logic methods. Results of the fuzzy logic and questionnaires were in strong agreement with each other. This analysis therefore showed landscape, crowdedness, and light are the principal factors that significantly impact safety. Finally, we have shown that the analysis of fuzzy logic can easily be extended and used in other locations. 


\section{References}

Baum, K., \& Klaus, P. (2005). Violent victimization of college students, 1995-2002. Age.

Bledsoe, L., \& Sar, B. (2001). Campus survey report: safety perception and experiences of violence. Retrieved fromhttp://static.prisonpolicy.org/scans/bjs/vvcs00.pdf.

Blockley, D. (1975). Predicting the likelihood of structural accidents. ICE Proceedings. Retrieved from http://www.icevirtuallibrary.com/content/article/10.1680/iice p.1975.3633.

Blockley, D. (1979). The role of fuzzy sets in civil engineering. Fuzzy Sets and Systems. Retrieved from http://www.sciencedirect.com/science/article/pii/0165011479900010.

Brown, C. (1980). The merging of fuzzy and crisp information. Journal of the Engineering Mechanics Division. Retrieved fromhttp://cedb.asce.org/cgi/WWWdisplay.cgi?9311.

Crowe, T. (2000). Crime prevention through environmental design: Applications of architectural design and space management concepts (p.49).

Hadipriono, F. (1985). Assessment of falsework performance using fuzzy set concepts. Structural Safety. Retrieved fromhttp://www.sciencedirect.com/science/article/pii/0167473085900074

Hadipriono, F. (1988). Fuzzy set concepts for evaluating performance of constructed facilities. Journal of Performance of Constructed Facilities.Retrieved fromhttp://ascelibrary.org/doi/abs/10.1061/(ASCE)0887-3828(1988)2:4(209).

Hadipriono, F., \& Fujino, T. (1994). Fuzzy fault tree analysis for construction safety. Proc., Int. Conf. on Information Processing and Management of Uncertainty in Knowledge-Based Systems.

Hedayati, M. (2009). Perception of crime and an assessment of crime prevention through environmental design (CPTED) elements in a housing area: A case study of Minden. University Science Malaysia, Pulau Pinang.

Kuo, F., Bacaicoa, M., \& Sullivan, W. (1998). Transforming inner-city landscapes trees, sense of safety, and preference. Environment and Behavior. Retrieved fromhttp://eab.sagepub.com/content/30/1/28.short

Kuo, F., \& Sullivan, W. (2001). Environment and crime in the inner city does vegetation reduce crime? Environment and Behavior.Retrieved fromhttp://eab.sagepub.com/content/33/3/343.short

Larimian, T., Zarabadi, Z. S. S., \& Sadeghi, A. (2013). Developing a fuzzy AHP model to evaluate environmental sustainability from the perspective of Secured by Design scheme - A case study. Sustainable Cities and Society, 7, 25-36. Retrieved from http://www.sciencedirect.com/science/article/pii/S2210670712000625

McConnell, E. (1997). Fear of crime on campus: A study of a southern university. Journal of Security Administration. Retrieved from http://search.proquest.com/openview/11c9731b3e8c9a5b1dc2271cfc66273d/1?pq origsite=gscholar

Minnery, J., \& Lim, B. (2005). Measuring crime prevention through environmental design. Journal of Architectural and Planning Research. Retrieved fromhttp://www.jstor.org/stable/43030751 
Sakip, S. R. M., Johari, N., \& Salleh, M. N. M. (2012). The Relationship between Crime Prevention through Environmental Design and Fear of Crime. Procedia - Social and Behavioral Sciences, 68, 628-636. Retrieved fromhttp://www.sciencedirect.com/science/article/pii/S1877042812057370

Steinmetz, N. M., \& Austin, D. M. (2013). Fear of Criminal Victimization on a College Campus: A Visual and Survey Analysis of Location and Demographic Factors. American Journal of Criminal Justice, 39(3), 511-537. Retrieved fromhttp://link.springer.com/article/10.1007/s12103-013-9227-1).

\section{Copyrights}

Copyright for this article is retained by the author(s), with first publication rights granted to the journal.

This is an open-access article distributed under the terms and conditions of the Creative Commons Attribution license (http://creativecommons.org/licenses/by/4.0/). 